\title{
Modified Flower Pollination Algorithm Constrained Optimal Power Flow
}

\author{
Tahtah Hocine*, Arif Salem
}

LACOSERE Laboratory Amar Telidji University Electrical Engineering Department, Laghouat 3006, Algeria

Corresponding Author Email: h.tahtah47@gmail.com

\section{https://doi.org/10.18280/isi.240412}

Received: 9 April 2019

Accepted: 26 June 2019

\section{Keywords:}

power system, optimal power flow, global optimization, flower pollination algorithm (FPA), security constrained

\begin{abstract}
In power systems, the power flow must satisfy a set of operational and safety requirements. It is a highly nonlinear problem to optimize the power flow. In this paper, the flower pollination algorithm (FPA) is modified and applied to optimize the power flow. Firstly, the author set up a mathematical model for power flow optimization problem, and formulated all the constraints. Next, the FPA was introduced in details, including the self-pollination, cross-pollination and other operations. After that, the local search strategy of the FPA was modified to replace the worst individuals in the current population with the best individuals in the previous population. Finally, the modified FPA (MFPA) was proved more efficient and better in convergence than standard algorithms like the firefly algorithm.
\end{abstract}

\section{INTRODUCTION}

The optimal power flow (OPF) problem has been studied for decades, and determining the settings of control variables for economic and secure operation of a power system has been the main purpose of all OPF programs. Due to recent complexity of the operating conditions, new mathematical models have been created and they have been used to solve this problem.

For many years, classical programming methods are used to solve OPF such us Gradient method $[1,2]$ linear programming (LP) and non linear programming (NLP) [3, 4], in the literature we find also Newton methods [5-10] and quadratic programming (QP) $[11,12]$. As these methods have proven their efficiency,

They have been vastly applied to several Optimal Power Flow problems. However, the efficiency of these methods is limited, when the situations encountered in practice involve one or more complications: for example, the objective function can be non-linear, or even not express itself analytically as a function of the parameters; or the problem is multi objective [13].

Through the huge improvements in the capacity of the computers and the arrival of a new class of methods, called meta-heuristics, marks a reconciliation of this area: Indeed, they apply to all kinds of problems. These methods include genetic algorithms [14], Evolutionary Programming (EP) [15, 16], taboo search method [17], ant colony algorithms [18, 19], Particle Swarm Optimization (PSO) [20-22] etc. these methods appeared with a common goal: face out to the difficult optimization problems.

It is worth the mention that other techniques are used to solve the OPF, such as Cuckoo Search Algorithm (CSA) [2325] and firefly optimization algorithm [26-29].

Developed by X. S. Yang in 2012, Flower Pollination Algorithm, it is one of the most modern optimization techniques that targeted optimization issues [30].

This algorithm, as stimulated from nature, simulates the features of flowering plants and the important aspects that lead to find the global and the local feasible space. As for these features, it has been used to solve the optimal power flow problem [31-34].

The main goal of this work is the minimization of fuel cost, voltage deviation and power losses (PL) using a modified flower pollination algorithm. where the IEEE 30-bus system is taken as test system.

This work is structured as follows: Firstly, the mathematical formulation of OPF is given; followed by the presentation of the FPA. Afterwards, a description of the Modified FPA technique is presented then applied to OPF.

A presentation of a comparative study, consisting of a comparison of results from the literature against FPA, Firefly Algorithm (FFA) and MFPA using three objective functions is given; at the end, some comments about the achieved results.

\section{MATHEMATICAL FORMULATION}

The OPF is a nonlinear optimization problem where its main objective is to obtain the optimum power system operating conditions. In general, the OPF problem is formulated as follows [1]:

$$
\begin{gathered}
\min f(x, u) \\
\text { Subject to: } g(x, u)=0 \\
h(x, u) \leq 0
\end{gathered}
$$

where, $f(x, u)$ is the objective function, in general given by:

Fuel Cost Function [1]

$$
f\left(P_{g}\right)=\sum_{i=1}^{n g}\left(\alpha_{i}+\beta_{i} P_{g i}+\gamma_{i} P_{g i}\right)
$$

where, $\alpha_{i}, \beta_{i}$ and $\gamma_{i}$ are the cost coefficients of ith unit. 
Active power losses function $[36,36]$

$$
f=\min (P L)
$$

Voltage deviation function [37, 39]

$$
f=\sum_{k=1}^{L n p q}\left|V_{l 1}-1\right|
$$

State variables are shown in Eq. (5).

$$
x^{T}=\left[V_{L 1}, \ldots, V_{L n p q}, P_{G 1}, Q_{G 1}, \ldots, Q_{G n p v}, S_{L 1}, \ldots, S_{L n t l}\right]
$$

where, $\mathrm{V}_{\mathrm{L}}$ the load bus voltages; $\mathrm{P}_{\mathrm{G} 1}$ is the slack bus active power; $\mathrm{Q}_{\mathrm{G}}$ the reactive power generation of the units; $\mathrm{S}_{1}$ the transmission line loading; $N P Q$ the number of load bus, $N P V$ the number of controlled bus; and NTL the number of transmission lines.

Control variables are presented in Eq. (6).

$$
u^{T}=\left\lfloor V_{G 1}, \ldots, V_{G n g}, P_{G 2}, \ldots, P_{G n g}, Q_{c_{1}}, \ldots, Q_{c n}, T_{1}, \ldots, T_{n t}\right\rfloor
$$

where, $\mathrm{V}_{\mathrm{G}}$ is generator voltages, $N C$ and $N T$ respectively, are the number of shunt VAR compensators and number of taps changing transformers, $\mathrm{T}$ is the tap setting of the tap changing transformers and $\mathrm{Q}_{\mathrm{C}}$ is the output of shunt VAR compensators.

\subsection{Equality constrains}

Power Flow Equations:

$$
\begin{aligned}
& P_{g k}-P_{l k}-V_{k} \sum_{m=1}^{n b}\left[V_{m}\left[g_{k m} \cos \left(\delta_{k}-\delta_{m}\right)+b_{k m} \sin \left(\delta_{k}-\delta_{m}\right)\right]=0\right. \\
& Q_{g k}-Q_{l k}-V_{k} \sum_{m=1}^{n b}\left[V_{m}\left[g_{k m} \sin \left(\delta_{k}-\delta_{m}\right)-b_{k m} \cos \left(\delta_{k}-\delta_{m}\right)\right]\right]=0
\end{aligned}
$$

where,

$P_{g k}$ is the active generation of the $k^{t h}$

$Q_{g k}$ is the reactive generation of the $k^{\text {th }}$ unit, $Q_{l k}$ and $P_{l k}$ are reactive and active power demand on $k^{\text {th }}$ bus,

$V_{k}$ and $V_{m}$ are the voltage value of $k^{\text {th }}$ and $m^{\text {th }}$ bus,

\subsection{Inequality constrains}

Generator limits:

$$
\begin{gathered}
V_{i}^{\text {min }} \leq V_{i} \leq V_{i}^{\text {max }} \\
\text { Pgimin } \leq \text { Pgi } \leq \text { Pgimax } \\
\text { Qgimin } \leq \text { Qgi } \leq \text { Qgimax }
\end{gathered}
$$

Compensators limits:

$$
q_{i}^{\min } \leq q_{i} \leq q_{i}^{\max }
$$

where, $i=1 \ldots \mathrm{nc}$, nc: number of compensators.
Tap limits transformer:

$$
T_{i}^{\min } \leq T_{i} \leq T_{i}^{\max }
$$

where, $\mathrm{i}=1 \ldots \mathrm{nt}$, nt: number of transformers.

Voltages at loading buses:

$$
V_{j}^{\min } \leq V_{j} \leq V_{j}^{\max }
$$

where, $\mathrm{j}=1 \ldots \mathrm{npq}$, npq: loading buses.

Transmission line limits:

$$
S_{i}^{\min } \leq S_{i} \leq S_{i}^{\max }
$$

where, $i=1, \ldots n t l, n t l$ n number of transmission lines loading. In case of violation of control variables limits, the following variables are limited:

$$
u_{i}= \begin{cases}u_{i}^{\max } & u_{i}>u_{i}^{\max } \\ u_{i}^{\min } & u_{i}<u_{i}^{\min }\end{cases}
$$

In case of violation of state variables limits the penalty function is introduced in the objective function Where $\mathrm{J}$ is the new objective function:

$$
J(x, u)=f(x, u)+\sum_{i=1}^{p}\left(x_{i}-x_{i}^{\lim }\right)^{2}
$$

\section{THE FLOWER POLLINATION ALGORITHM}

The reproduction in plants occurs by union of the gametes. The male gametes produce pollen grains and female gametes produce ovules; it is essential that the pollen has to be moved to the stigma for the union. Pollination is the process of transfer and deposition of pollen grains from anther to the stigma of flower. The process of pollination is ensured by an agent. In agriculture, the pollination is necessary to generate seeds and fruits [34]. There are two sorts of pollination.

\subsection{Self-pollination}

Self-pollination happens when a flower contains the male and the female gametes and the fertilization is done by pollen from the same flower or flowers of the same plant.

\subsection{Cross-pollination}

Cross-Pollination happens when pollen grains are moved to a flower from another plant. The procedure of cross fertilization results with the assistance of abiotic or biotic operators for example birds, bats, insects, ... etc.

When the fertilization happens without participation of external agents, this pollination is abiotic. Only about $10 \%$ of plants fall in this category. Biotic Pollination is the process of pollination which needs external pollinators to move the pollen from the anther to the stigma.

The plants with strong odour and coloured petals attract honey bees, beetles, moths, ants, wasps and butterflies thus the insect pollination occurs. The availability of nectar attracts 
insects to flowers, edible pollen and when insect stands on the flower, the pollen grains stick to the body. When the insect visits another flower, the pollen is moved to stigma enabling pollination. The pollination is also facilitated by birds and bats.

Flower Pollination Algorithm (FPA) is developed by XinShe Yang in 2012 the four rules of this algorithm are [34]:

- (Rule 1): Cross-pollination and the biotic are the global pollination and the pollinators pursue the Levy distribution.

- (Rule 2): Self-pollination and the abiotic are the local pollination.

- (Rule 3): The flower consistency property can be considered as a propagation ratio that is relative to the level of similarity between two flowers.

- (Rule 4): local fertilization has a slight favorable position over global fertilization. because of the physical proximity and wind.

The main steps of FPA are illustrated below:

\begin{tabular}{|c|}
\hline $\begin{array}{c}\text { Objective min or max } f(x), x=x_{1}, \ldots x_{d} \\
\text { generate population radomly } \\
\text { Find the current best solution } g^{*} \\
\text { Identify } p \in[0,1] a \text { switch probability } \\
\text { while }(i<\text { maxGen) } \\
\text { foreach flower } \\
\text { if rand }<p, \\
\text { else } \\
\text { Global pollination via } x_{i}^{+1}=x_{t}^{t}+\gamma L\left(g^{*}-x_{t}^{t}\right) \\
\text { select two solution randomly } \\
\text { Local pollination via } x_{t}^{t+1}=x_{t}^{t}+\varepsilon\left(x_{j}^{t}-x_{t}^{t}\right) \\
\text { end if } \\
\text { Evaluate new solutions } \\
\text { Update solutions with better new ones } \\
\text { end for } \\
\text { Keep the current best solution } g^{*} \\
\text { end while }\end{array}$ \\
\hline
\end{tabular}

Figure 1. Pseudo code of the Flower Pollination Algorithm (FPA)

\section{MODIFIED FLOWER ALGORITHM (MFPA)}

POLLINATION

The idea is if a no amelioration of solution is noticed during evaluations the modified algorithm select the best individuals from the previous population and replace the worsts individuals, as a result a new population is created.

The goal is to ameliorate the quality of solution by making a local search around the best individuals, the results show that this modification give a good result comparing with PSO and standard FPA.

\section{RESULT}

To demonstrate the attitude of the proposed algorithm the IEEE 30-bus system is considered as test system [36]. In order to find the global solutions to a different objective functions the algorithm was written in MATLAB and applied in HP Core i7 with a RAM of $8 \mathrm{~GB}$.

To see the superiority of proposed approach, all the parameters of FPA and MFPA are fixed and the number of evaluations is limited at 25000 evaluations.

Three functions are used to evaluate the performance of the proposed algorithm. The simulations results are shown in the following sections.

\subsection{Evaluation of fuel cost function}

The objective is to find the total fuel cost of active power of all generation units the minimum cost were obtained by MFPA $799.265 \$ / h$ and the Table 1 gives the comparison between proposed algorithm and the other algorithms.

Table 1. Best control variables (fuel cost minimization)

\begin{tabular}{|c|c|c|c|c|c|}
\hline & \multicolumn{5}{|c|}{ Fuel Cost Minimization } \\
\cline { 2 - 6 } & $\begin{array}{c}\text { EGA } \\
{[40]}\end{array}$ & $\begin{array}{c}\text { MSA } \\
{[41]}\end{array}$ & FFA & FPA & MFPA \\
\hline P1 & 177.285 & 177.21 & 177.03 & 178.09 & 177.30 \\
\hline P2 & 48.93 & 48.73 & 48.69 & 48.98 & 48.38 \\
\hline P5 & 21.29 & 21.45 & 21.30 & 21.05 & 21.31 \\
\hline P8 & 20.49 & 21.06 & 21.13 & 19.99 & 21.04 \\
\hline P11 & 11.93 & 11.96 & 11.94 & 11.97 & 11.96 \\
\hline P13 & 12.23 & 12.00 & 12.00 & 12.10 & 12.09 \\
\hline V1 & 1.098 & 1.0848 & 1.1000 & 1.1000 & 1.1000 \\
\hline V2 & 1.08 & 1.0653 & 1.0861 & 1.0855 & 1.0875 \\
\hline V5 & 1.053 & 1.0338 & 1.0588 & 1.0572 & 1.0610 \\
\hline V8 & 1.062 & 1.0382 & 1.0660 & 1.0653 & 1.0673 \\
\hline V11 & 1.08 & 1.0927 & 1.0991 & 1.1000 & 1.0876 \\
\hline V13 & 1.078 & 1.0453 & 1.0873 & 1.0864 & 1.0992 \\
\hline T11 & 0.975 & 1.0490 & 1.0132 & 0.9652 & 0.9565 \\
\hline T12 & 1.05 & 0.9387 & 0.9077 & 0.9996 & 0.9982 \\
\hline T15 & 1.0125 & 0.9701 & 0.9255 & 0.9316 & 0.9507 \\
\hline T36 & 1.0125 & 0.9749 & 0.9604 & 0.9619 & 0.9619 \\
\hline QC12 & 0.01 & 2.57 & 0.24 & 3.81 & 3.10 \\
\hline QC15 & 0.04 & 4.20 & 2.51 & 2.53 & 4.05 \\
\hline QC17 & 0.02 & 5 & 2.15 & 4.80 & 4.00 \\
\hline QC20 & 0.03 & 3.68 & 1.03 & 2.44 & 3.00 \\
\hline QC21 & 0.01 & 4.95 & 1.44 & 3.40 & 3.07 \\
\hline QC23 & 0.03 & 3.08 & 3.28 & 0.77 & 0.22 \\
\hline QC24 & 0.02 & 4.98 & 2.73 & 5.00 & 4.01 \\
\hline QC29 & 0.01 & 2.48 & 2.58 & 2.47 & 2.07 \\
\hline Cost (\$/h) & 799.56 & 800.5099 & 799.3268 & 799.285 & $\mathbf{7 9 9 . 2 6 5}$ \\
\hline $\begin{array}{c}\text { Power } \\
\text { losses } \\
\text { (MW) }\end{array}$ & 8.755 & 9.0345 & 8.6937 & 8.7729 & 8.6833 \\
\hline $\begin{array}{c}\text { Voltage } \\
\text { deviations }\end{array}$ & - & 0.9035 & 1.9923 & 1.9890 & 1.9904 \\
\hline $\begin{array}{c}\text { Number of } \\
\text { evaluations }\end{array}$ & - & - & 25000 & 25000 & 25000 \\
\hline & & & & & \\
\hline
\end{tabular}

\subsection{Evaluation of active power losses function}

The proposed algorithm was applied to minimize the active power losses of the system. The obtained results are compared to FFA and standard FPA, it is clear that the proposed algorithm gives the best result as mentioned in Table 22.928 MW.

\subsection{Improvement of load buses voltage profile}

To have a good voltage performance, the voltage deviation at each load bus must to be as small as possible. The minimization of total deviation by the proposed algorithm (MFPA) gives us butter result comparing with the result obtained from BBO [42], MDE [43], MFPA, FPA, and FFA all the results are shown in the Table 3. 
Table 2. Best control variables (power losses minimization)

\begin{tabular}{|c|c|c|c|c|c|}
\hline & \multicolumn{5}{|c|}{ Power losses Minimisation IEEE 30-Bus } \\
\hline & EGA [40] & MSA [41] & FFA & FPA & MFPA \\
\hline P1 & 51.674 & 51.50 & 51.31 & 51.55 & 51.39 \\
\hline P2 & 79.97 & 80 & 80 & 80 & 79.98 \\
\hline P5 & 50 & 50 & 50 & 50 & 50 \\
\hline P8 & 35 & 35 & 35 & 34.99 & 34.97 \\
\hline P11 & 30 & 30 & 30 & 29.95 & 30 \\
\hline P13 & 40 & 40 & 40 & 39.85 & 39.99 \\
\hline V1 & 1.0518 & 1.0618 & 1.0986 & 1.0994 & 1.0999 \\
\hline V2 & 1.0488 & 1.0576 & 1.0939 & 1.0948 & 1.0976 \\
\hline V5 & 1.0270 & 1.0381 & 1.0744 & 1.0762 & 1.0794 \\
\hline V8 & 1.0306 & 1.0442 & 1.0814 & 1.0835 & 1.0849 \\
\hline V11 & 1.0612 & 1.0720 & 1.0805 & 1.0818 & 1.0986 \\
\hline V13 & 1.0382 & 1.0590 & 1.0876 & 1.0976 & 1.0959 \\
\hline T11 & 1.0750 & 1.0907 & 0.9687 & 0.9662 & 0.9755 \\
\hline T12 & 0.9500 & 0.9000 & 0.9886 & 1.0072 & 1.0472 \\
\hline T15 & 0.9875 & 0.9978 & 0.9442 & 0.9591 & 0.9674 \\
\hline T36 & 1.0125 & 0.9765 & 0.9712 & 0.9665 & 0.9755 \\
\hline QC12 & 0.04 & 0.76 & 1.80 & 0.08 & 5 \\
\hline QC15 & 0.02 & 4.22 & 3.53 & 3.4 & 4.98 \\
\hline QC17 & 0.05 & 5 & 0.43 & 2.95 & 4.82 \\
\hline QC20 & 0.03 & 3.96 & 3.14 & 0.36 & 4.28 \\
\hline QC21 & 0.01 & 5 & 4.28 & 4.94 & 4.91 \\
\hline QC23 & 0 & 3.01 & 3.36 & 5 & 0.78 \\
\hline QC24 & 0.03 & 4.99 & 2.29 & 1.83 & 4.68 \\
\hline QC29 & 0.04 & 2.32 & 1.33 & 2.05 & 2.3 \\
\hline Cost (\$/h) & 967.9300 & 967.6636 & 967.2522 & 966.7892 & 967.1363 \\
\hline Power losses (MW) & 3.244 & 3.1005 & 2.9404 & 2.9457 & $\mathbf{2 . 9 2 8 8}$ \\
\hline Voltage deviations & - & - & 2.0014 & 2.0425 & 2.0293 \\
\hline Number of evaluations & - & - & 25000 & 25000 & 25000 \\
\hline & & & & & \\
\hline
\end{tabular}

Table 3. Best control variables (voltage deviation minimization)

\begin{tabular}{|c|c|c|c|c|c|}
\hline & \multicolumn{5}{|c|}{ Voltage MinimisationIEEE 30-Bus } \\
\hline & BBO [42] & MDE [43] & FFA & FPA & MFPA \\
\hline P1 & 173.67 & 175.976 & 122.13 & 136.81 & 93.73 \\
\hline P2 & 049.06 & 49.5071 & 61.53 & 64.33 & 55.25 \\
\hline P5 & 021.77 & 21.8567 & 34.24 & 37.84 & 46.88 \\
\hline P8 & 023.27 & 21.4375 & 30.07 & 19.38 & 33.87 \\
\hline P11 & 013.84 & 12.4782 & 24.12 & 13.63 & 29.68 \\
\hline P13 & 011.98 & 12.0094 & 17.79 & 18.83 & 28.72 \\
\hline V1 & 1.0185 & 1.0420 & 1.0285 & 1.0366 & 1.0200 \\
\hline V2 & 1.0048 & 0.9849 & 1.0257 & 1.0309 & 1.0129 \\
\hline V5 & 1.0145 & 1.0144 & 1.0185 & 1.0174 & 1.0199 \\
\hline V8 & 1.0092 & 0.9988 & 1.0040 & 1.0047 & 1.0048 \\
\hline V11 & 1.0510 & 1.0516 & 1.0001 & 0.9806 & 0.9768 \\
\hline V13 & 1.0184 & 0.9876 & 1.0587 & 0.9960 & 1.0720 \\
\hline T11 & 1.0718 & 1.0718 & 1.0159 & 0.99348 & 0.9888 \\
\hline T12 & 0.9000 & 0.9000 & 0.9537 & 0.96259 & 0.9584 \\
\hline T15 & 1.0000 & 0.9410 & 1.0548 & 0.96932 & 1.0994 \\
\hline T36 & 0.9710 & 0.9706 & 0.9728 & 0.97439 & 0.9518 \\
\hline QC12 & 0.0370 & 1.2600 & 1.26 & 5.00 & 0.38 \\
\hline QC15 & 0.0500 & 4.9921 & 1.89 & 4.85 & 4.98 \\
\hline QC17 & 0.0000 & 0.0036 & 0.70 & 1.58 & 0.04 \\
\hline QC20 & 0.0500 & 5.0000 & 3.92 & 4.09 & 4.97 \\
\hline QC21 & 0.0500 & 4.9996 & 2.83 & 2.19 & 1.57 \\
\hline QC23 & 0.0500 & 4.9954 & 4.84 & 4.34 & 3.87 \\
\hline QC24 & 0.0500 & 4.9997 & 2.19 & 3.70 & 3.79 \\
\hline QC29 & 0.0300 & 2.6488 & 2.91 & 3.01 & 0.19 \\
\hline Cost (\$/h) & 805.75 & 803.79 & 835.09 & 833.21 & 892.17 \\
\hline Power losses (MW) & 10.18 & 9.8653 & 6.4799 & 7.4373 & 4.7121 \\
\hline Voltage deviations & 0.0951 & 0.0941 & 0.0975 & 0.0929 & $\mathbf{0 . 0 8 9 3}$ \\
\hline Number of evaluations & - & - & 25000 & 25000 & 25000 \\
\hline & & & & & \\
\hline
\end{tabular}




\section{CONCLUSION}

In this work, the application of MFPA method for solving optimal power flow problem has been presented. The fuel cost, the active power losses and the voltage deviation were minimized through optimization of control variable, the achieved results on IEEE 30 bus system test have been illustrated, the proposed algorithm gives as better results compared with standard FPA and FFA which confirm the robustness of proposed algorithm.

For the future researches it is recommended to use the proposed method to a multi-objective problem. to confirm the effectiveness of the proposed method.

\section{REFERENCES}

[1] Dommel, H., Tinney, W. (1968). Optimal power flow solutions. IEEE Trans. Power Appar. Syst., PAS-87(10): 1866-1876. https://doi.org/10.1109/TPAS.1968.292150

[2] Salgado, R., Brameller, A., Aitchison, P. (1990). Optimal power flow solutions using the gradient projection method. Part 1: Theoretical basis. IEE Proceedings-C Gener. Transm. Distrib., 137(6): 424-428. https://doi.org/10.1049/ip-c.1990.0057

[3] Kirschen, D.S., Van Meeteren, H.P. (1988). MW/voltage control in a linear programming based optimal power flow. IEEE Trans. Power Syst., 3(2): 481-489.

[4] de Sá Ferreira, R. (2013). A mixed-integer linear programming approach to the AC optimal power flow in distribution systems. IEEE Trans. Power Syst., 29(5): 2447-2459. https://doi.org/10.1109/59.192899

[5] Santos, A.J. (1995). Optimal-power-flow solution by Newton's method applied to an augmented Lagrangian function. IEE Proc. - Gener. Transm. Distrib., 142(1): 33. https://doi.org/10.1049/ip-gtd:19951586

[6] De Medeiros, M.F.J., Filho, M.C.P. (1998). Optimal power flow in distribution networks by Newton's optimization methods. ISCAS '98. Proc. 1998 IEEE Int. Symp. Circuits Syst. (Cat. No.98CH36187), 3: 505-509. https://doi.org/10.1109/ISCAS.1998.704060

[7] Lib, R., Chena, L., Yokoyamab, R. (2001). Stability constrained optimal power flow by inexact Newton method. IEEE Porto Power Tech Conference 2001. https://doi.org/10.1109/PTC.2001.964709

[8] Tinney, W.F., Ashley, B., Brewer, B., Hughes, A. (1984). Optimal power flow by newton approach. IEEE Power $\begin{array}{lll}\text { Eng. } & \text { Rev., } & \text { PER-4(10): }\end{array}$ https://doi.org/10.1109/TPAS.1984.318284

[9] Wibowo, R.S., Penangsang, O. (2013). Dynamic DC optimal power flow using quadratic programming. 2013 International Conference on Information Technology and Electrical Engineering (ICITEE), Yogyakarta, Indonesia. https://doi.org/10.1109/ICITEED.2013.6676268

[10] Wibowo, R.S., Maulana, R., Taradini, A., Pamuji, F.A., Soeprijanto, A. (2015). Quadratic programming approach for security constrained optimal power flow. 2015 7th International Conference on Information Technology and Electrical Engineering (ICITEE), Chiang Mai, Thailand. https://doi.org/10.1109/ICITEED.2015.7408941

[11] Leeton, U., Uthitsunthorn, D., Kwannetr, U., Sinsuphun, N., Kulworawanichpong, T. (2010). Power loss minimization using optimal power flow based on particle swarm optimization. Electr. Eng. Comput. Telecommun. Inf. Technol. ECTICON 2010 Int. Conf., pp. 440-444.

[12] Kil, U. (2013). Transient stability constrained optimal power flow solution of Ac-Dc systems using genetic algorithm. 2013 3rd International Conference on Electric Power and Energy Conversion Systems, Istanbul, Turkey. https://doi.org/10.1109/EPECS.2013.6712996

[13] Yuryevich, J., Wong, K.P. (1999). Evolutionary programming based optimal power flow algorithm. Power Syst. IEEE Trans., 14(4): 1245-125. https://doi.org/10.1109/59.801880

[14] Chung, C.Y. (2004). A parallel evolutionary programming based optimal power flow algorithm and its implementation. 3rdInt. Conf. on Machine Learning and Cybernetics, Shanghai, China, pp. 26-29. https://doi.org/10.1109/ICMLC.2004.1382232

[15] Ren, P., Li, N. (2014). Multi-objective optimal power flow solution based on differential harmony search algorithm. 2014 10th International Conference on Natural Computation (ICNC), Xiamen, China. https://doi.org/10.1109/ICNC.2014.6975856

[16] Sreejith, S., Chandrasekaran, K., Simon, S.P. (2009). Touring ant colony optimization technique for optimal power flow incorporating thyristor controlled series compensator. 2009 World Congress on Nature \& Biologically Inspired Computing (NaBIC), Coimbatore, India. https://doi.org/10.1109/NABIC.2009.5393815

[17] Soares, J., Sousa, T., Vale, Z.A., Morais, H., Faria, P. (2011). Ant colony search algorithm for the optimal power flow problem. 2011 IEEE Power and Energy Society General Meeting, Detroit, MI, USA. https://doi.org/10.1109/PES.2011.6039840

[18] Ku-Mahamud, K.R. (2015). Hybrid ant colony system and flower pollination algorithms for global optimization. 2015 9th Int. Conf. IT Asia Transform. Big Data into Knowledge, CITA 2015 - Proc., 2015. https://doi.org/10.1109/CITA.2015.7349816

[19] Leeton, U., Uthitsunthorn, D., Kwannetr, U., Sinsuphun, N., Kulworawanichpong, T. (2010). Loss power minimization using optimal power flow based on particle swarm optimization. The 2006 IEEE International Joint Conference on Neural Network Proceedings, Vancouver, BC, Canada, pp. 440-444. https://doi.org/10.1109/IJCNN.2006.246945

[20] Turkay, B.E., Cabadag, R.I. (2013). Optimal power flow solution using particle swarm optimization algorithm. Eurocon 2013, Zagreb, Croatia. https://doi.org/10.1109/EUROCON.2013.6625164

[21] Rao, N.T. (2015). Optimal reactive power flow control for minimization of active power losses using particle swarm optimization. 2015 Conf.on Power, Control, Communication and Computational Technologies for Sustainable Growth (PCCCTSG), pp. 38-41. https://doi.org/10.1109/PCCCTSG.2015.7503954

[22] Ponnusamy, A., Rengarajan, N. (2014). Optimal power flow solution using cuckoo search algorithm. Journal of Engineering and Aplied Research, 9(12): 2687-2691.

[23] Singh, S.P., Rokadia, J., Mishra, C. (2015). Optimal power flow in the presence of wind power using modified cuckoo search. IET Gener. Transm. Distrib., 9(7): 615-626. https://doi.org/10.1049/iet-gtd.2014.0285

[24] Baysal, Y.A., Member, S., Altas, I.H., Member, S. (2016). Cuckoo search algorithm for power loss 
minimization by optimal capacitor allocation in radial power systems. 2016 International Symposium on INnovations in Intelligent Systems and Applications (INISTA), Sinaia, Romania https://doi.org/10.1109/INISTA.2016.7571822

[25] Li, C.L., Zhao, H.Z., Chen, T.C. (2010). The hybrid differential evolution algorithm for optimal power flow based on simulated annealing and tabu search. 2010 International Conference on Management and Service Science, Wuhan, China. https://doi.org/10.1109/ICMSS.2010.5578512

[26] Hasan, Z., El-Hawary, M.E. (2014). Optimal power flow by black hole optimization algorithm. 2014 IEEE Electrical Power and Energy Conference, Calgary, AB, Canada. https://doi.org/10.1109/EPEC.2014.43

[27] Herbadji, O., Nadhir, K., Slimani, L., Bouktir, T. (2013). Optimal power flow with emission controlled using firefly algorithm. 2013 5th International Conference on Modeling, Simulation and Applied Optimization (ICMSAO), Hammamet, Tunisia. https://doi.org/10.1109/ICMSAO.2013.6552559

[28] Rajan, A., Malakar, T. (2014). Optimal active power dispatch using hybrid firefly algorithm. 2014 Annual IEEE India Conference (INDICON), Pune, India. https://doi.org/10.1109/INDICON.2014.7030642

[29] Sarangi, S.K., Panda, R., Priyarshini, S., Sarangi, A. (2016). A new modified firefly algorithm for function. 2016 International Conference on Electrical, Electronics, and Optimization Techniques (ICEEOT), Chennai, India. https://doi.org/10.1109/ICEEOT.2016.7755239

[30] Yang, X.S. (2012). Flower pollination algorithm for global optimization. In: Unconventional Computation and Natural Computation, Lecture Notes in Computer Science, 7445: 240-249. https://doi.org/10.1007/978-3642-32894-7_2

[31] Regalado, J.A., Emilio, B.E., Cuevas, E. (2015). Optimal power flow solution using modified flower pollination algorithm. 2015 IEEE International Autumn Meeting on Power, Electronics and Computing (ROPEC), Ixtapa, Mexico. https://doi.org/10.1109/ROPEC.2015.7395073

[32] Chakraborty, D., Saha, S., Maity, S. (2015). Training feedforward neural networks using hybrid flower pollination-gravitational search algorithm. 2015 International Conference on Futuristic Trends on Computational Analysis and Knowledge Management (ABLAZE), Noida, India. https://doi.org/10.1109/ABLAZE.2015.7155008

[33] Pandya, K.S., Dabhi, D.A., Joshi, S.K. (2015). Comparative study of bat \& flower pollination optimization algorithms in highly stressed large power system. 2015 Clemson University Power Systems Conference (PSC), Clemson, SC, USA. https://doi.org/10.1109/PSC.2015.7101677

[34] Vijayaraj, S. (2016). Multi-area economic dispatch using flower pollination algorithm. 2016 International Conference on Electrical, Electronics, and Optimization Techniques (ICEEOT), Chennai, India. https://doi.org/10.1109/ICEEOT.2016.7755541

[35] Reddy, S.S., Bijwe, P.R., Abhyankar, A.R. (2014). Faster evolutionary algorithm based optimal power flow using incremental variables. Int. J. Electr. Power Energy Syst., 54 :

198-210. https://doi.org/10.1016/j.ijepes.2013.07.019

[36] Mohamed, A.A.A., Mohamed, Y.S., El-Gaafary, A.A.M., Hemeida, A.M. (2017). Optimal power flow using moth swarm algorithm. Electr. Power Syst. Res., 142: 190-206. https://doi.org/10.1016/j.epsr.2016.09.025

[37] Bhattacharya, A., Chattopadhyay, P.K. (2011). Application of biogeography-based optimisation to solve different optimal power flow problems. IET Gener. Transm. Distrib., 5(1): 70. 10.1049/iet-gtd.2010.0237

[38] Nayak, M.R., Krishnanand, K.R., Rout, P.K. (2011). Modified differential evolution optimization algorithm for multi-constraint optimal power flow. 2011 International Conference on Energy, Automation and Signal, pp. 1-7. https://doi.org/10.1109/ICEAS.2011.6147113

[39] Bhowmik, A.R., Babu, K.N. (2014). Multi objective optimal power flow using NSMOGSA. IEEE International Conference on Circuit, Power and Computing Technologies, Noorul Islam University, Kumaracoil, K.K Dist, Tamilnadu, India.

[40] Bhowmik, A.R., Chakraborty, A.K. (2014). Optimal reactive power flow using non dominated sorting multi objective gravitational search algorithm. IEEE Electrical Engineering/Electronics,

Computer, Telecommunications and Information Technology (ECTI-CON 2014), Thailand. https://doi.org/10.1109/ECTICon.2014.6839706

[41] Chung, C.Y., Yan, W., Liu, F. (2011). Decomposed predictor-corrector interior point method for dynamic optimal power flow. Power Syst. IEEE Trans., 26(3): 1030-1039. https://doi.org/10.1109/TPWRS.2010.2080326

[42] Trivedi, I.N., Parmar, S.A., Bhesdadiya, R.H., Jangir, P. (2016). Voltage stability enhancement and voltage deviation minimization using ant-lion optimizer algorithm. 2016 2nd International Conference on Advances in Electrical, Electronics, Information, Communication and Bio-Informatics (AEEICB), Chennai, India. https://doi.org/10.1109/AEEICB.2016.7538286

[43] Tuaimah, F.M., Abd, Y.N., Meteb, M.F. (2011). Optimal power flow problem for Iraqi national super high voltage grid based on interior point method (IPM). 2011 IEEE PES Conf. Innov. Smart Grid Technol. - Middle East, pp. $1-5$. MidEast.2011.6220826 https://doi.org/10.1109/ISGT- 